\title{
An alternate approach for deriving rock slope shear strength parameters within weak jointed rock masses
}

\author{
S Narendranathan Infra Tech Pty Ltd, Australia
}

S McBeath Infra Tech Pty Ltd, Australia

K Ayemin Infra Tech Pty Ltd, Australia

EC Lee Infra Tech Pty Ltd, Australia

\begin{abstract}
A variety of rock mass strength models are used by rock mechanics practitioners to evaluate the strength of a rock mass, which will ultimately resolve its integrity (stability) within a slope. It is the author's intent to emphasise the differences in the mechanical behaviour of weak foliated rock masses, in comparison to stronger rock masses, and highlight that when dealing with weak materials in a low confinement environment, careful consideration needs to be given to defining the limit state strengths. This is particularly significant when dealing with foliated materials that have significant structural control. In the author's experience, the typically used Barton Bandis shear strength evaluation process for defect plane shear strength evaluation can sometimes overestimate strengths at low confinement. The approach put forward by Ryan (2005), appears to be more appropriate for assessing defect plane shear strengths at low confinements. This approach however remains somewhat limited in its development and use. The authors have applied Ryan's method in back analysing shear strengths for an instability that occurred within a weathered and jointed rockmass. The results proved useful for site specific use, in future designs, though further work is required to make this relationship generally applicable.
\end{abstract}

\section{Introduction}

A variety of rock mass strength models Jaeger (1971), Barton and Bandis (1982), Call (1985) are used by rock mechanics practitioners to evaluate the strength of rock masses and associated defect planes (geological structure), which will ultimately define the stability of a slope. Typically, when assessing the stability of weak and foliated rock masses for open pits, a Mohr-Coulomb strength model is applied to evaluate the strength of the intact rock component; and the Barton Bandis model is utilised to evaluate the defect plane shear strength.

In most pit slope problems, a shear type failure criterion is conventionally assumed, in this scenario the total strength mobilised by a rock mass hinges upon the confinement effected, i.e. the normal force. In a weak isotropic rock mass (circular) failure the confinement is very closely related to the depth of failure and the density of the material. However, in weak, foliated or jointed rock masses the instability mechanisms are usually a 'thinner skinned' mechanism that at a significantly lower confinement, and the resistance to sliding is governed by the 'resistance' mobilised along the asperities of a geological structure. In most of these cases the rock mass overall strength matrix is governed by a complex interaction of the apparent friction against sliding mobilised along the defect plane surface and the resistance provided by the 'bridge' afforded by the intact rock. Hence the strength mobilised is closely linked to the depth and geometry of the instability.

This paper will highlight through the presentation of a case study (that the authors were involved in a forensic capacity) that outlines the limitations of the conventional strength models, when dealing with instabilities at low confinements and identifies a more appropriate strength model put forward by Ryan (2005). 


\subsection{Preamble to case study}

Over the last 30 years, there has been, and currently is, a high reliance on complex numerical models incorporating ever more complicated rock mass deformation algorithms to quantify and predict slope stability. In addition, the development of computing power facilitated the rapid analysis of numerous iterations of complex slope scenarios. The present day slope engineer has become, to some extent, sidelined by this technology, and some fundamental aspects of detection and assessment are being overlooked.

The above aspects are further exacerbated by increased concern regarding safety, whereby, engineers are not generally allowed to access a failure in the pit slope to effectively assess the contributing factors, i.e. cut off structures, their termination characteristics, the strength of fault gouge etc. It should be noted that the authors by no means condone unsafe practices; however, the lack of the intimate assessment does have the potential to cloud the overall assessment i.e. it is not possible to properly model rock masses if we do not understand how they behave; the only way we can truly understand the behaviour of any given material is to comprehend how it fails. These particular aspects will be highlighted below in the impending case study in addition to putting forward an alternative process of evaluating rock mass strength parameters at low confinement.

\section{Case study}

This case study highlights the importance of diligently scrutinising the failure geometry to correctly identify the critical failure mechanism and determine the most appropriate process by which to analyse the instability. In this particular scenario the offending features defining the failure geometry and slope instability mechanism were not correctly recognised. As a result, inappropriate remediation measures were initially proposed.

\section{$2.1 \quad$ Geological setting}

The study rock mass is a highly to moderately weathered dolerite metamorphosed to greenschist facies. Intact rock strengths range between 5-20 MPa, the specific gravity of the material was typically in the order of 1.8 .

The degree of weathering makes identification and mapping of structures challenging, however the structural sets observed within fresh dolerite immediately beneath the area are believed to be present:

- Set 1 - Sub vertical major faults trending sub parallel to the pit slope.

- Set 2 - Foliation parallel minor joints (persistence less than $5 \mathrm{~m}$ ) and major joints (persistence of 5-50 m) dipping into the slope at approximately $70^{\circ}$, the joint spacing could be 'close' at times.

- Set 3 - Shallow to moderately dipping major joints/faults striking sub parallel to the slope and dipping pitwards.

- Set 4 - Sub vertical faults striking approximately perpendicular to the pit slope and having persistence of $100 \mathrm{~m}+$ but widely spaced.

The mean rock mass rating $\left.\left(\mathrm{RMR}_{89}, 14\right]\right)$ of the rock mass in the vicinity of the failure was assessed as approximately 35, as shown in Table 1. 
Table 1 RMR89 of the rock mass, case study 1

\begin{tabular}{ll}
\hline \multicolumn{1}{c}{ Parameter } & \multicolumn{1}{c}{ Rating or condition } \\
\hline Strength & $30-40 \mathrm{MPa}$ \\
Rating & 4 \\
\hline Rock quality designation (\%) & $\sim 20 \%$ \\
Rating & 3 \\
\hline Fracture spacing $(\mathrm{mm})$ & $60-200 \mathrm{~mm}$ \\
Rating & 8 \\
\hline Condition of discontinuities & Smooth to rough, minor infill, otherwise as described above. \\
\hline Rating & (NB Base friction angle was $11^{\circ}$, from direct shear testing) \\
\hline Groundwater & 10 \\
\hline Rating & Damp \\
\hline RMR & 10 \\
\hline
\end{tabular}

\subsubsection{Slope design and mining methodology}

The pit slope was mined with conventional open pit load and haul methodologies using trucks and face shovels with excavators undertaking the final batter face excavation. The slope design geometry was as follows:

- Vertical batter height $-30 \mathrm{~m}$, N.B. the pit was excavated in $10 \mathrm{~m}$ high benches.

- Batter face angle $-60^{\circ}$.

- Berm width $-7 \mathrm{~m}$.

- Inter-ramp angle - approximately $51^{\circ}$.

- Overall slope angles - varied between 48 and $50^{\circ}$ depending on the inclusion of ramps.

\subsection{Slope failure}

Several weeks prior to the failure a number of tension cracks were noted on the berms adjacent to the wall in question. These cracks were noted by the site geotechnical engineers and were monitored; initially they were dilating at an accelerating rate, however this subsided over a subsequent two-week period. Immediately after this two-week period the failure occurred, with no notable signs to presage it. The failure is shown in Figure 1. 


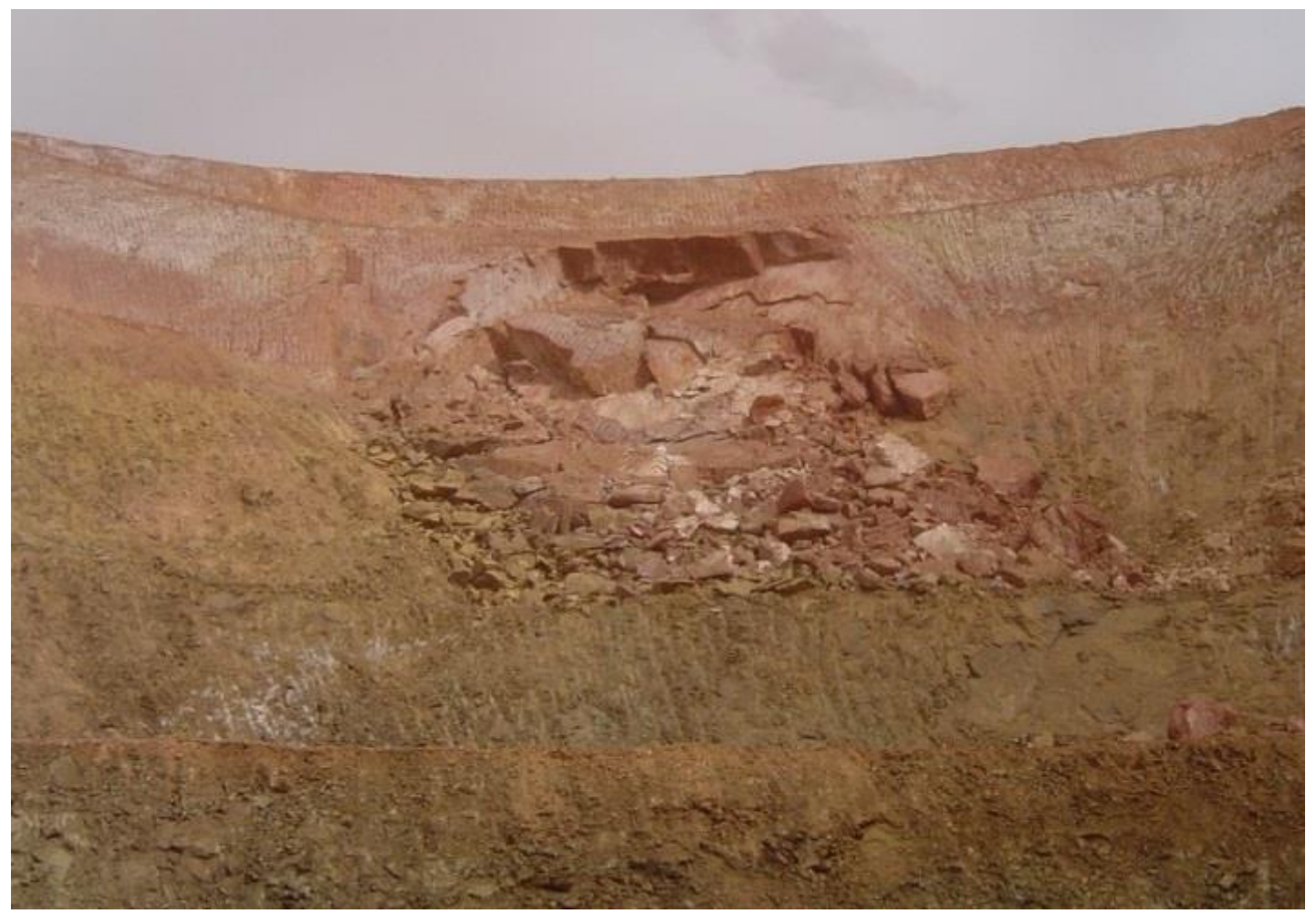

Figure 1 View of the failure from below

\subsection{Original diagnosis}

As the instability occurred in the weathered horizon of the pit wall, the original forensic evaluation focused on the possibility that this instability was a circular or rotational failure. Although the authors' were not involved in the original assessment of the instability, it is understood that very little in the way of a detailed forensic evaluation assessing other mechanisms was undertaken.

\subsubsection{Originally proposed remedial actions}

The pit wall had a planned strike length of approximately $1.2 \mathrm{~km}$ to be formed within a weathered horizon extending to a depth of 70 to $100 \mathrm{~m}$ below surface. At the time the failure occurred there was a further $700 \mathrm{~m}$ of pit wall to be developed. To mitigate the onset of any further instabilities a recommendation was put forward to flatten the overall slope angles to approximately $47^{\circ}$, i.e. an overall flattening of approximately $4^{\circ}$. This was based on the outcomes from revised estimates of rock mass shear strengths and the results of updated stability modelling (back analysis). It should be noted that the back analysis undertaken did not incorporate a detailed survey of the post failure pit wall geometry, but rather focused on the fact that the failure was circular in nature and involved iteratively manipulating the rock mass shear strength parameters (cohesion and friction) for the existing pit wall geometry until a Factor of Safety (FS) of less than 1.0 was achieved. This combination of cohesion and friction was deemed to represent the shear strength parameters of the pit wall at the time of failure. These parameters were subsequently used to forward analyse stable slope geometry, resulting in the $47^{\circ}$ recommendation.

\subsubsection{Outcomes subsequent to implementation of remedial actions}

Prior to the implementation of the flatter $\left(47^{\circ}\right)$ slope design; another failure (similar in character to the existing failure) occurred approximately $300 \mathrm{~m}$ to the north of the present instability, presaged by the same signs, as shown in Figure 2. However, this time, the failure occurred in an area which was still accessible on foot hence it was possible to obtain a closer view of the contributing factors. It was at this point that the authors were called upon by the mine management to be involved in the forensic evaluation of the previous and most recent instability. 


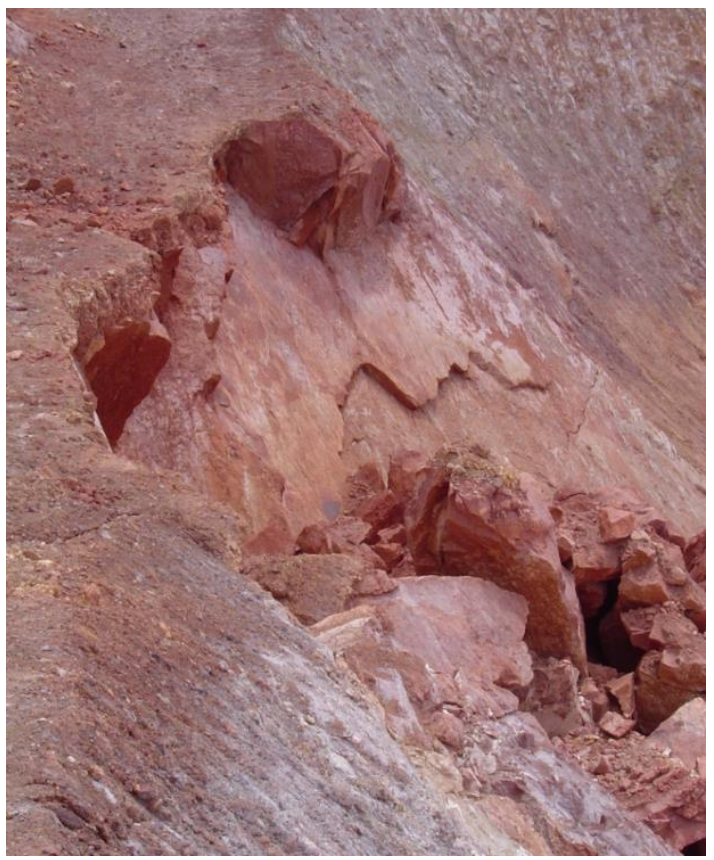

Figure 2 Close up view of the back-scarp from the crest adjacent to the failure

\subsubsection{Observations on the most recent instability}

It was now possible to assess the instability area to clearly determine the failure geometry. It became evident that there was a structural control to the instability, as can be seen in Figure 2. Upon further scrutiny, the following aspects were uncovered:

- The controlling geological structures were dipping at approximately $46^{\circ}$ pitwards, and tended to have full batter to multiple batter scale continuity up dip and up to $80 \mathrm{~m}$ along strike. Given that these features were dipping flatter than the current pit face, they would daylight in intermittent locations down dip of the wall.

- These structures are noted at depth, within the fresh horizon of the pit, but there they were generally healed. The defect surfaces were generally planar smooth, thereby mobilising very little shear strength along the defect plane surfaces.

- Upon undertaking a review of the geotechnical core logs and photos of the area these structures were noted to occur in certain intervals within the drill core. However, as the occurrence of these features were deemed to be intermittent they were not carried forward in the design process. To appreciate the implications of this decision, it is necessary to look at the instability mechanism in more detail and understand the forces and geometries involved.

- The sizes of failed blocks were typically no greater than $5 \mathrm{~m}$, however were noted to vary in size from 1 to $5 \mathrm{~m}$, with typical block sizes in the order of $3 \mathrm{~m}$.

\subsection{Revised interpretation of instability mechanism}

Based on observations the authors concluded that the instability was a result of a planar sliding mechanism as opposed to a circular failure mechanism; where persistent structures dipping at approximately $46^{\circ}$ were undercut by a $51^{\circ}$ slope face.

The pit walls were well above the water table; the mine site does not lie in an area of high seasonal rainfall. Majority of the blocks formed seem to have geometrically shaped well defined edges, and varied in size from 1 to $5 \mathrm{~m}$ in length/height. The likely damage mechanism is exfoliation along pre-existing open or weakly healed defect planes, which was probably exacerbated by blasting. Furthermore, the effect of excavation unloading creates a 'stress relieved' zone behind the pit face, reducing confinement and affecting shear strength. 


\subsection{In depth look at instability mechanism(s) involved}

In weak and foliated rock masses such as those present within instability, there are typically three types of deformation behaviour commonly observed, as described by Ryan (2005) as follows:

- At low confinements: Generally intact rock breakage does not occur (unless the rock is very weak), hence the failure mechanism is one of shearing along or over the asperities of the defect surface and/or block rotation.

- At intermediate confinements: At this point there is a transition from solely shearing along/through asperities and block rotation to including rock mass failure due to intact rock breakage.

- At high confinements: At these levels of confinements, any present rock bridges are heavily confined and essentially prevent block rotation or sliding along the defect plane asperities. The only achievable mechanism would be intact shear failure through the rock.

Barton and Bandis (1982) identified the above criteria based on the results of his biaxial loading tests. Defining the relationship between these three 'qualitative' stress states and identifying the point at which one mechanisms ceases to be dominant and the other takes over (i.e. the transition zone), in particular for heavily jointed rock masses, proved to be the main challenge. This is also acknowledged by Ryan (2005). The case study presented demonstrates that not properly accounting for the strength and stress relationship at low stresses can produce non conservative results.

The limitations associated with the Barton Bandis correction factors have been covered previously Narendranathan (2011); particularly when dealing with planar sliding instabilities at low confinement.

The authors chose to adopt Ryan's (2005) approach, which identified a number of crucial aspects relevant to this study. Ryan's work extends and refines concepts presented by others, such as Deere and Miller (1966), Patton (1966), Barton and Bandis (1982), Call (1985) and others, however the main advances in Ryan's work was identifying the following:

- Identifying that the percentage of intact rock strength that is mobilised between joints is proportional to the joint intensity, an estimate of the percentage of intact rock strength mobilised along a failure path would exponentially increase as the joint length to spacing ratio decreases.

- As most joint failure paths are not continuous, there remains some cohesion effect between joints even at very low normal stress levels. This minimum cohesion effect can be seen in many benched slopes within open pit mines. Experience indicates that some residual shear strength exists at normal stresses approaching zero, even for a failure path with very well developed, persistent jointing. The strength $(T)$ at such low stress along a joint path is affected by the interlocking effect of the rock blocks between joints. This is difficult to quantify and requires some knowledge of the geology as well as engineering judgement.

Ryan, modified the joint shear strength power curve discussed by Jaeger (1971), Barton (1976), and Call (1985). A power law defines the 'curve' effect better at low confinements. This relationship took the form:

$$
\tau=K \sigma^{m}
$$

where:

$\mathrm{K}$ and $\mathrm{m}$ are site specific constants.

If we were to apply this formulation to derive (i.e. back calculate) a revised shear strength function, we need to calibrate it to our specific in situ conditions. Based on observations on site we knew the following:

- The depth of failure in all cases were relatively shallow between 1 to $5 \mathrm{~m}$ (i.e. the size of the largest block), however these instabilities were exacerbated over time and manifested as ongoing 
'fretting' and sloughing, which may have made the depth of failure seem larger (deeper) than it actually was.

- As the depth of failure was limited to approximately $5 \mathrm{~m}$, it was indicative of some degree of large scale (mechanical) interlocking effected at that degree of confinement. Our current challenge is to adequately quantify the effects of mechanical interlocking as a result of the intact rock bridge and frictional resistance afforded by the defect plane strength, with respect to the above relationship.

To develop the above relationships further, we need to quantify confinement for the respective blocks sliding along the defect planes. For the purpose of this assessment the evaluation has only been taken on the structures in the direction of the sliding (daylight envelope), i.e. it is assumed that these structures will be aligned in the orientation of the maximum shear stress. Figure 3 depicts the differing levels of shear strength mobilised as a result of the varying block sizes.

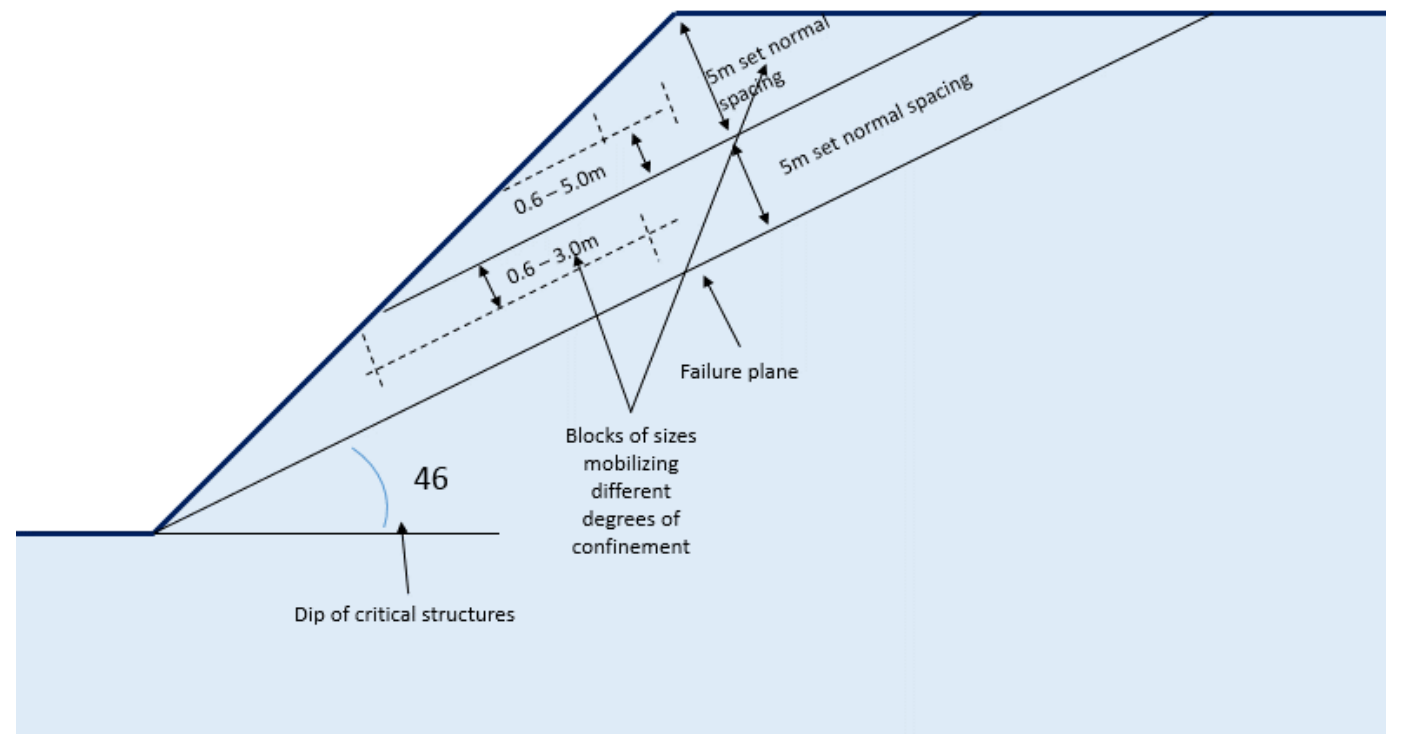

Figure 3 Blocks of varying sizes mobilise different degrees of strength

If we move away from the idea of thinking about block sizes, but rather how these blocks develop confinement as a result of their 'weight' and resistance to sliding along a plane, we can develop the chart shown below in Figure 4, labelled 'driving force'.

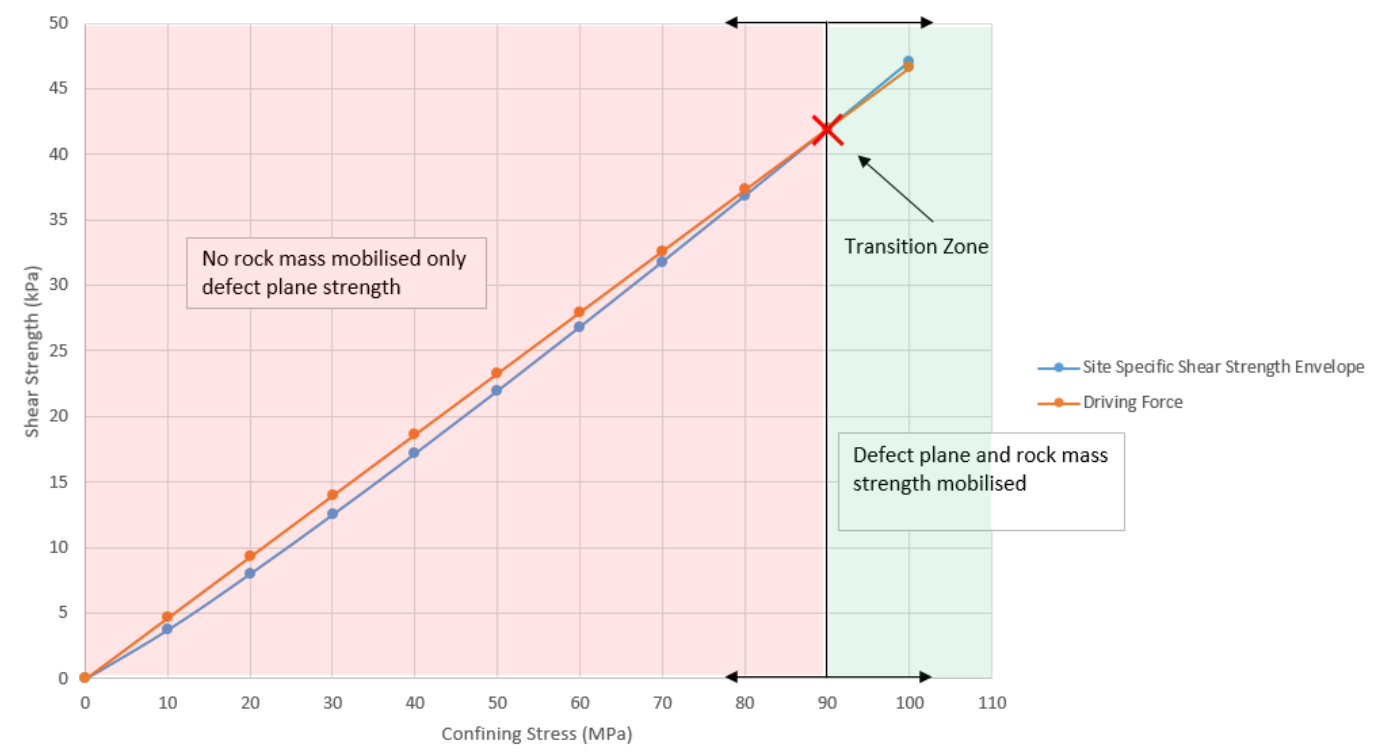

Figure 4 Revised shear strength envelope depicting the 'transitional' stress zone 
Based on the above points we can calibrate a site specific shear strength envelope, using a power curve, ensuring the following points are borne in mind:

- For confinements less than $55 \mathrm{kPa}$ (block sizes <3.0) the shear strength envelope should plot below the driving force curve; i.e. all blocks less than $3 \mathrm{~m}$ 'failed'.

- The depth of failure is typically restricted to $5 \mathrm{~m}$ i.e. a confinement of $90 \mathrm{kPa}$, this indicates the 'transition' zone or stress as defined by Ryan, where full or a higher degree of interlocking takes effect.

Based on the above the following curve was derived shown in Figure 4, plotted in relation to the driving force as labelled in the figure above.

To achieve this curve, the following site constants have to be utilised, in the following relationship, $\tau=K \sigma^{m}$ :

- $\mathrm{K}-0.297$.

- $\mathrm{M}-1.100$.

\subsection{Rock strength versus joint intensity}

Ryan identified that the degree of mobilised intact rock strength is proportional to the intensity of jointing. The intensity of jointing can be quantified in a number of different ways, i.e. fracture frequency, rock quality designation (RQD) or the ratio of the joint length to joint spacing.

This exercise was undertaken for this site. Based on field observations (of joint spacing and length information), and our site specific curve we had an idea of the mobilised rock mass strength, hence we are able to plot a chart (Figure 5) correlating the joint intensity (ratio of joint length to spacing) to the percent of mobilised rock strength.

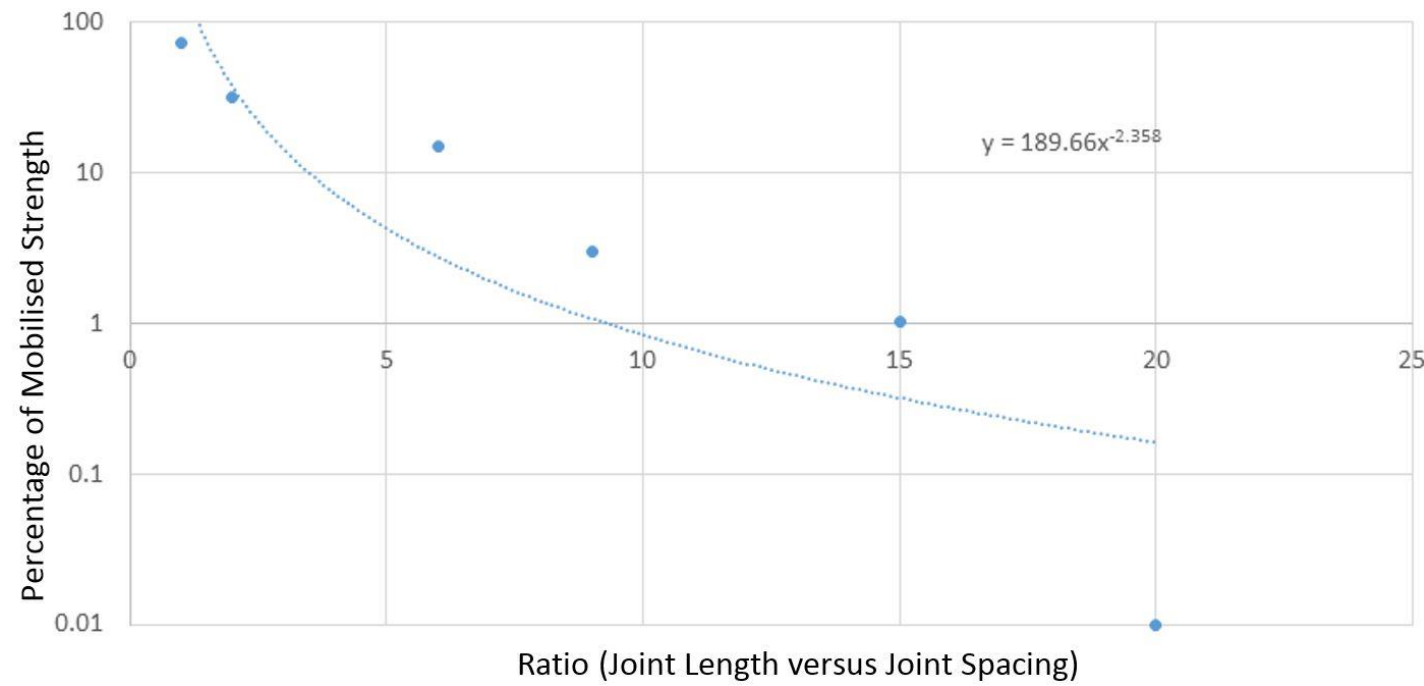

Figure 5 Site specific curve for mobilised rock strength versus joint intensity

This process of correlation is something that can be challenging to calibrate in the field even with the benefit of deformation monitoring data.

The approach that the authors used is acknowledged as subjective and would require further verification. The following process was applied by the authors:

- In reference to Figure 4 above, it is evident that the transitional stress (TS) is approximately $90 \mathrm{kPa}$, correlating with a $5 \mathrm{~m}$ block. We know at confinements less than $90 \mathrm{kPa}$, little to no rock mass strength is mobilised hence any afforded shear strength has to be activated by deflect plane asperities therefore all blocks less than $5 \mathrm{~m}$ in size regardless of jointing intensity would be expected to fail. 
- There were however a few blocks that were between 3 to $5 \mathrm{~m}$ in size as depicted in Figure 2 that were noted to have been stable. Blocks this size correspond to confinements of less than $90 \mathrm{kPa}$; hence in reference to Figure 4 (i.e. transitions strength noted as $90 \mathrm{kPa}$ ) one would not expect any rock mass shear strength to be mobilised. However, it is clear that there is additional strength being mobilised which keeps the blocks in place. The authors attribute this additional strength to a proportion of the rock mass shear strength.

- The authors used a simplistic calibration process which involved undertaking a sliding analysis for blocks between 3 and $5 \mathrm{~m}$ in size using the criterion presented below in Figure 6 . In these instances, the authors iteratively increased the resisting forces (R) until a FS of approximately 1.0 was achieved. The resulting value could be approximated to the shear resistance afforded. This level of shear resistance in all cases was more than what was afforded by available defect plane resistance i.e. Barton and Bandis (1990). The authors chose to attribute this 'additional' strength as being partly mobilised from the rock mass i.e. this can be expressed as a percentage of the overall rock mass shear strength.

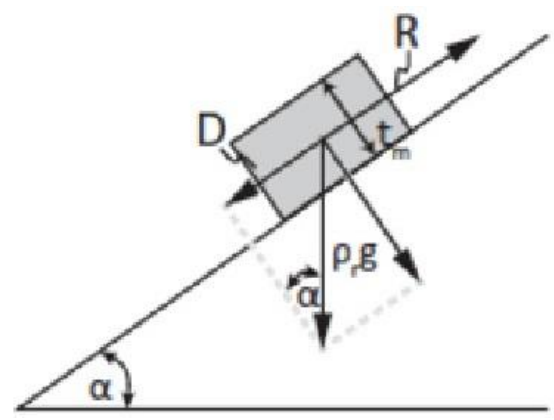

Figure 6 Mechanics of a block sliding on an inclined plane

where:

$$
\begin{aligned}
& D=\text { driving force } \\
& R=\text { resisting forces } \\
& \varphi=\text { internal angle of friction } \\
& \alpha=\text { local hillslope gradient }
\end{aligned}
$$

- Hence it would now be possible to plot the joint intensity expressed as a ratio of joint length to joint spacing as done in Figure 5. The degree of joint intensity had to be assessed visually where possible hence it is acknowledged that there are some limitation which should be further refined.

The above relationship is specific to the study site and can be now used by the site engineers when revising the designs for the remaining $1.2 \mathrm{~km}$ of pit wall in the same geological unit(s). This assumes that general rock mass characteristics (RQD etc.) as well as defect plane orientation are commensurate if this chart is to be used as a predictive tool.

It highlights the effect of joint intensity on the degree of overall mobilised rock strength, hence this provides an indication to the designer as to what proportion the mobilised rock mass shear strength needs to be reduced by when incorporating it into design calculations or numerical models. At high joint intensities the degree of rock mass strength mobilised is small, and the effects of joint plane roughness plays a governing factor, (referred to by Ryan as base cohesion), which is best represented using a power law rather than the conventionally used Barton and Bandis criteria as it can over estimate strength at low levels of confinement.

\section{Discussion and further work}

The 'transitional zone', (i.e. the normal stress at which the behaviour of the blocks within the rock mass changes as the applied confinement increases), is closely tied to the intensity of the jointing; whereby the 
more intensely jointed the rock mass the more susceptible the individual blocks are to rotation, as opposed to intact shearing.

The confinement at which this occurs is crucial as it controls the stress - strength relationship of the rock mass, and is a crucial indicator of depth of failure. Knowing the approximate location of the depth of failure provides important input when designing slope monitoring systems, i.e. placement of prisms, inclinometers etc.

Based on the case study, the transition zone occurred at approximately $90 \mathrm{kPa}$. Ryan's premise is that the TS is a function of joint intensity, and the basic friction angle.

$$
\mathrm{TS}=\mathrm{F}(\mathrm{Ji}, \phi)
$$

where:

$\mathrm{Ji}$ - Joint Intensity, now this is not only a function of RQD or say fracture frequency, but also the number of well-defined joint sets. This is particularly crucial at low confinements, as the better defined joint sets are; there is a greater susceptibility for individual block rotation to occur. Therefore, this aspect of joint intensity probably needs to consider, not only RQD or fracture frequency, but also individual joint sets, this can be represented say by using Barton's (1974) In (Joint Number for $Q$ ) or simply as the number of individual joint sets.

$\Phi$ - The basic (base) friction angle, as determined either from tilt testing or direct shear testing.

The primary driver for adopting Ryan's shear strength methodology was to numerically attempt to quantify the observations noted during the process of undertaking forensic evaluations. It is the authors' intent to develop this approach further building on work done by Ryan (2005) and Narendranathan (2011), to better develop the relationships to appropriately allow for the effects of joint intensity. It is the authors' intent to also develop relationships for rock masses of different geological characteristics (i.e. geomorphology etc.) so as to enable the formulation of a general (power law) strength model that would be applicable across a variety of geological and structural settings.

\section{Acknowledgement}

The authors would like to thank the Infra Tech Group and its clients for providing consent to publish these findings.

\section{References}

Barton, NR 1974, A review of the shear strength of filled discontinuities in rock, Norwegian Geotechnical Institute, no. 105, Oslo.

Barton, NR 1976, 'The shear strength of rock and rock joints', International Journal of Rock Mechanics and Mining Sciences, vol. 13, no. 10, pp. 1-24.

Barton, NR \& Bandis, SC 1982, 'Effects of block size on the shear behaviour of jointed rock', in 23rd U.S. Symposium on Rock Mechanics, Berkeley, pp. 739-760.

Barton, NR \& Bandis, SC 1990, 'Review of predictive capabilities of JRC-JCS model in engineering practice', in N Barton \& O Stephansson (eds), International Symposium on Rock Joints, Rotterdam, Balkema, pp. 603-610.

Call, RD 1985, 'Evaluation of material properties', in MK McCarter (ed.), Design of Non-Impounding Mine Waste Dumps, pp. 35-46.

Deere, DU \& Miller, RP 1966, Engineering classification and index properties of rock, technical report no. AFNL-TR-65-116, Albuquerque, Air Force Weapons Laboratory.

Jaeger, JC 1971, 'Friction of rocks and stability of rock slopes', Géotechnique, Eleventh Rankine Lecture, vol. 21, no. 2, pp. 97-134.

Narendranathan, S 2011, 'Determination of shear strength parameters for foliated rock masses', in International Symposium on Slope Stability, Vancouver.

Patton, FD 1966, 'Multiple modes of shear failure in rock', in Proceedings of the First Congress of the International Society of Rock Mechanics, Lisbon, vol. 1, pp. 509-513.

Ryan, TM 2005, 'Shear Strength of Closely Jointed Porphyry Rock Masses', in 40th U.S. Symposium on Rock Mechanics, American Rock Mechanics Association, vol. 1, pp. 307-319. 